\title{
Effects of Renin-Angiotensin System Blockade and Dietary Salt Intake on Left Ventricular Hypertrophy in Dahl Salt-Sensitive Rats
}

\author{
Koh-ichi Sugimoto, Akio Fujimura, Izumi Takasaki*, Yasuo Tokita*, Tamio Iwamoto*, \\ Toshikazu Takizawa*, Eiji Gotoh*, Hiroshi Shionoiri*, and Masao Ishii*
}

\begin{abstract}
We studied the effects of chronic blockade of the renin-angiotensin system on hypertension and cardiac left ventricular hypertrophy (LVH) in Dahl salt-sensitive (DS) rats given a high-salt or low-salt diet. [Experiment 1] Twelve-week-old male DS rats were fed an $8 \% \mathrm{NaCl}$ diet and received the angiotensin II receptor $\left(\mathrm{AT}_{1}\right)$ antagonist, candesartan $(3 \mathrm{mg} / \mathrm{kg} / \mathrm{d})$, the angiotensin converting enzyme inhibitor enalapril $(30 \mathrm{mg} / \mathrm{kg} / \mathrm{d})$, or vehicle for $6 \mathrm{wk}$ after $3 \mathrm{wk}$ of $8 \%$ salt-loading. Neither candesartan nor enalapril with concomitant high salt-loading attenuated the blood pressure (BP) elevation. LVH was also not attenuated significantly by these treatments. [Experiment 2] After $8 \mathrm{wk}$ of $8 \%$ salt-loading, the rats were given a $0.3 \% \mathrm{NaCl}$ diet and concurrently received candesartan, enalapril, or vehicle for 5 wk. Switching from the high-salt to low-salt diet significantly decreased BP and left ventricular mass in the vehicle-treated animals. Both candesartan and enalapril normalized BP during salt-depletion; the blockade of the reninangiotensin system produced an additive reduction in LVH. These findings suggest that sodium intake and hemodynamic load, but not the renin-angiotensin system, may be major determinants of the development of LVH in DS rats. (Hypertens Res; 21: 163-168)
\end{abstract}

Key Words: angiotensin II receptor antagonist, angiotensin converting enzyme inhibitor, cardiac hypertrophy, dietary salt, Dahl salt-sensitive rat

Numerous studies have demonstrated that angiotensin II (Ang II) plays a key role in the development and maintenance of hypertensive cardiac hypertrophy in experimental animals and humans. Blockade of Ang II receptors inhibits intracellular signaling of stretch-mediated hypertrophy of cultured cardiomyocytes, suggesting that pure mechanical stimuli can elicit myocardial cell hypertrophy by stimulating Ang II secretion from cardiomyocytes (1). It is thus conceivable that cardiac hypertrophy caused by mechanical (hemodynamic) load alone can be reduced by Ang II receptor antagonism.

Dietary high-salt intake causes cardiac hypertrophy and hypertension in Dahl salt-sensitive (DS) rats and suppresses plasma renin activity (PRA). Thus, it appears that cardiac hypertrophy in saltloaded DS rats is induced mainly by hemodynamic load, with only a small contribution from the reninangiotensin system. However, if activation of a local renin-angiotensin system (RAS) is involved in cardiac left ventricular hypertrophy (LVH), blockade of the RAS could reduce LVH even in salt-loaded DS rats. We have previously demonstrated that angiotensin type $\mathrm{I}\left(\mathrm{AT} \mathrm{T}_{1}\right)$ receptor antagonists did not blunt hypertension or reduce $\mathrm{LVH}$ in DS rats fed a $4 \% \mathrm{NaCl} \operatorname{diet}(2,3)$.

Our findings suggest that sodium intake plays a major role in the development of LVH and hypertension in salt-loaded DS rats, and that the tissue RAS might not be activated in DS rats fed a $4 \%$ $\mathrm{NaCl}$ diet. It has been reported that an $8 \%$ sodium loading initially suppressed PRA and then increased its value after a 4-wk period of high-salt loading in DS rats (4). These findings suggest that the circulating RAS is activated even in DS rats given an $8 \%$ $\mathrm{NaCl}$ diet for a longer period, and suggest the possibility that the tissue renin-angiotensin system in DS rats is also activated by long-term high salt loading. If the local RAS is activated in DS rats by long-term high-sodium intake, it may be involved in the development of cardiac hypertrophy in these animals.

To address this issue, we evaluated the effects on hypertension and cardiac LVH of chronic blockade of the RAS by the angiotensin converting enzyme (ACE) inhibitor and the $\mathrm{AT}_{1}$ receptor antagonist candesartan in DS rats given an $8 \%$ salt diet. In addition, we examined the effects of blockade of the RAS on blood pressure and cardiac hypertrophy after the RAS was activated by switching the rats

From the Department of Clinical Pharmacology, Jichi Medical School, Tochigi, Japan, and * Second Department of Internal Medicine, Yokohama City University School of Medicine, Yokohama, Japan.

Address for Reprints: Koh-ichi Sugimoto, M.D., Department of Clinical Pharmacology, Jichi Medical School, 3311-1 Minamikawachi-machi, Kawachi-gun, Tochigi 329-0498, Japan.

Received March 6, 1998; accepted in revised form April 27, 1998. 
from a high-salt to low-salt diet.

\section{Materials and Methods}

Male DS rats were obtained from Tsukuba Research Laboratory, Eisai Co., Ltd., Tokyo, Japan. The rats were maintained under controlled conditions of light, temperature, and humidity. During the acclimatization period, all animals had free access to tap water and standard rat chow containing $0.3 \% \mathrm{NaCl}$. The experiments were performed in accordance with the Institutional Guide for Laboratory Animals.

\section{Experiment 1}

At 12 wk of age, the rats received rat chow containing $8 \% \mathrm{NaCl}$ (Oriental Kobo Kogyo Co., Ltd., Tokyo, Japan). Three weeks later, the animals were randomly divided into three groups and were treated as follows for $6 \mathrm{wk}$, during which they received an $8 \% \mathrm{NaCl}$ diet. Candesartan cilexetil (TCV 116; (士)-1-(cyclohexyloxycarbonyloxy)ethyl 2-ethoxy-1[[2'-(1H-tetrazol-5-yl)biphenyl-4-yl]methyl]-1H-benzimidazole-7-carboxylate; Takeda Pharmaceutical industries, Ltd., Osaka, Japan) was given to rats in the first group $(n=10)$ at a dose of $3 \mathrm{mg} / \mathrm{kg}$ body weight per $d$ in the drinking water. The second group $(n=10)$ was given enalapril $(30 \mathrm{mg} / \mathrm{kg}$ per d) in the drinking water. The third group $(n=16)$ received tap water alone and served as control.

\section{Experiment 2}

From 12 to $20 \mathrm{wk}$ of age, the rats were fed $8 \%$ $\mathrm{NaCl}$ chow. After 8 wk of $8 \% \mathrm{NaCl}$-loading without drug treatment, the animals were randomly divided into four groups. In the first group $(n=11)$, heart weight was measured at the end of the 8 wk of saltloading; this group served as the high salt control. The remaining groups were given a $0.3 \% \mathrm{NaCl}$ diet and were simultaneously treated with drugs or vehicle for $5 \mathrm{wk}$. Candesartan $(3 \mathrm{mg} / \mathrm{kg}$ per d), enalapril $(30 \mathrm{mg} / \mathrm{kg}$ per d), and tap water alone were given to the second $(n=11)$, third $(n=11)$, and fourth $(n=$ 12) groups, respectively. Drugs were administered in the drinking water.

Candesartan was prepared in a small volume of dimethyl sulphoxide and dissolved in the drinking water. Enalapril was dissolved in distilled water and added to the drinking water. The concentrations and volumes of the drug solution were adjusted three times a week to ensure proper dosing. During the high-salt diet, average daily water intake was 55 to $60 \mathrm{ml}$ per animal. Candesartan was dissolved in the drinking water at a concentration of 1.8 to 2.3 $\mathrm{mg} / 100 \mathrm{ml}$, resulting in a daily intake of approximately $3 \mathrm{mg} / \mathrm{kg}$. Enalapril was dissolved in the drinking water at a concentration 10 -fold that of candesartan. After switching from the high-salt to low-salt diet, daily water intake decreased to about half that during a high-salt diet. The drugs were dissolved in the drinking water in double the concentrations used during the high-salt diet. Candesartan and enalapril were supplied by Takeda Chemical Industries, Ltd., Osaka, Japan, and Banyu Phar-

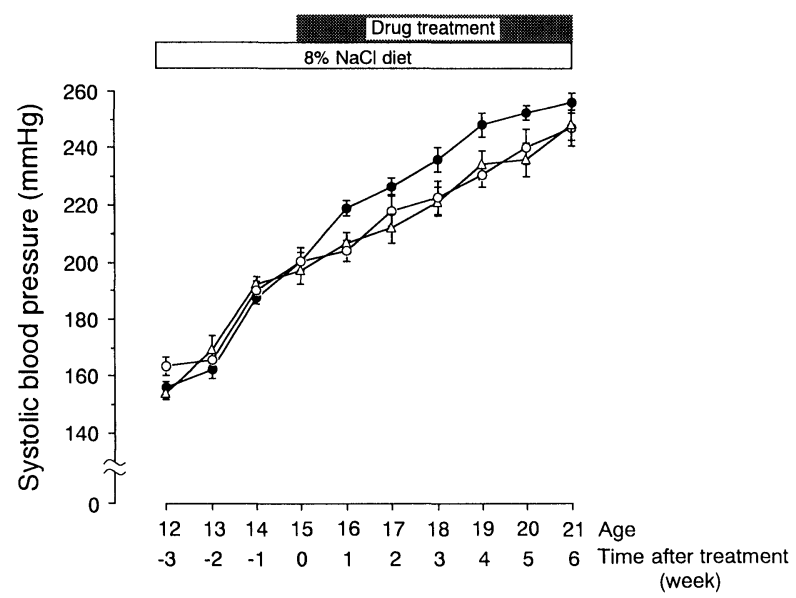

Fig. 1. Line graph shows changes in tail-cuff systolic blood pressure in Dahl salt-sensitive rats fed an $8 \% \mathrm{NaCl}$ diet. Treatment with vehicle $(O: \mathrm{n}=16)$, candesartan $(\bigcirc: \mathrm{n}$ $=10)$, or enalapril $(\triangle: \mathrm{n}=10)$ was initiated after 3 wk of high salt-loading and continued for $6 \mathrm{wk}$. Bars represent means $\pm S E M$.

maceutical Co. Ltd., Tokyo, Japan, respectively. The administered doses of the drugs were equipotent in terms of antihypertensive effect in spontaneously hypertensive rats (data not shown). Body weight was measured weekly. Systolic blood pressure (SBP) was recorded in prewarmed awake rats with an automatic tail-cuff sphygmomanometer (UR-5000, Ueda Co., Ltd., Tokyo, Japan).

The rats were killed by cervical dislocation after treatment. Blood samples for measurement of PRA were collected into prechilled EDTA tubes, and the plasma was stored at $-80^{\circ} \mathrm{C}$ until assay. PRA was determined by radioimmunoassay of the angiotensin I generated after $3 \mathrm{~h}$ of incubation.

The heart was quickly removed, and the whole heart was weighed. The left ventricle (the interventricular septum plus the left ventricle) was weighed after the atria and the right ventricular free wall were dissected from the interventricular septum. The left ventricular weight/body weight ratio was used as an index of left ventricular mass.

Data are expressed as the means \pm SEM. Statistical analyses were performed by analysis of variance (ANOVA). Differences were considered statistically significant when $p$ was less than 0.05 .

\section{Results}

\section{Blood Pressure}

In experiment 1, SBP increased continuously during $8 \% \mathrm{NaCl}$ intake in the vehicle group (Fig. 1). No significant attenuation of the rise in blood pressure was observed in the drug-treated rats $(p>0.10$ in the candesartan group and $p>0.05$ in the enalapril group $v s$. the vehicle group). At the end of treatment, SBP averaged $245 \mathrm{mmHg}$ in the candesartan group, $246 \mathrm{mmHg}$ in the enalapril group, and 254 $\mathrm{mmHg}$ in the vehicle group. 


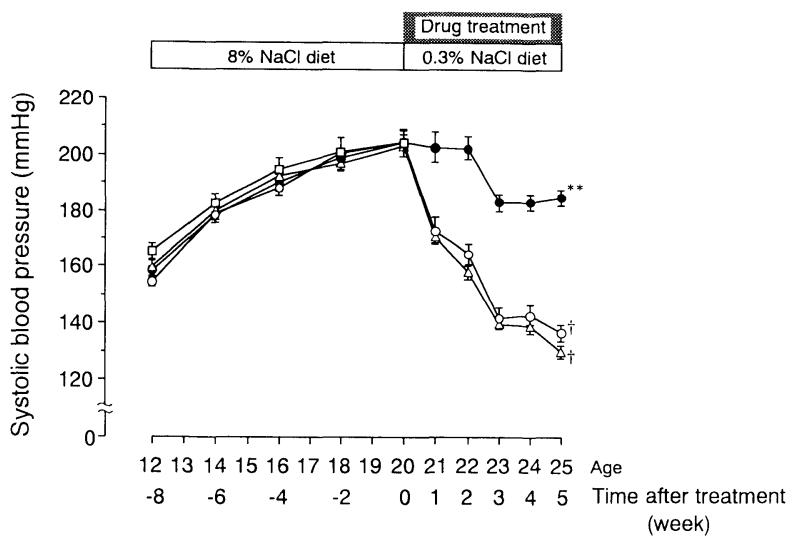

Fig. 2. Line graph shows changes in tail-cuff systolic blood pressure in Dahl salt-sensitive rats. All rats were fed an $8 \% \mathrm{NaCl}$ diet for $8 \mathrm{wk}$. The rats except the high-salt control were then switched to a $0.3 \% \mathrm{NaCl}$ diet and cotreated with vehicle $(O: \mathrm{n}=12)$, candesartan $(O: \mathrm{n}=11)$, or enalapril $(\triangle: \mathrm{n}=11)$ for $5 w k .{ }^{* *} \mathrm{p}<0.01$ vs. the high salt diet control rats $(\square: \mathrm{n}=11) .{ }^{\dagger} \mathrm{p}<0.0001$ vs. salt-depleted rats treated with vehicle. Bars represent means $\pm S E M$.

Figure 2 shows the time courses of SBP in DS rats during dietary salt-loading and subsequent saltdeprivation. In experiment $2, \mathrm{SBP}$ in DS rats increased from $157 \mathrm{mmHg}$ to $202 \mathrm{mmHg}$ during a high-salt diet for $8 \mathrm{wk}$. After switching from a high-salt to low-salt diet, SBP in the vehicle group remained at a similar level for $2 \mathrm{wk}$. Thereafter, SBP fell significantly, but did not return to the baseline level. In both the candesartan- and enalapril-treated groups, the reduction in SBP was significantly greater than that in the vehicle group $(p<0.0001)$. At the end of treatment, SBP decreased below the baseline levels in both the candesartan- and enalapril-treated groups. No significant differences were noted in SBP at any time point between the candesartan- and enalapril-treated groups.

\section{Left Ventricular Mass}

The effects of drug treatment on left ventricular mass in DS rats given high-salt and low-salt diets are shown in Fig. 3 and 4. In experiment 1, candesartan and enalapril did not significantly affect the left ventricular mass in DS rats fed an $8 \% \mathrm{NaCl}$ diet $(p<0.10)$. In experiment 2 , left ventricular mass was $2.68 \mathrm{~g} / \mathrm{kg}$ in the group that received an $8 \%$ $\mathrm{NaCl}$ diet for $8 \mathrm{wk}$ (the high-salt control). After switching from an $8 \%$ to $0.3 \% \mathrm{NaCl}$ diet, left ventricular mass decreased significantly in the vehicle group $(2.20 \mathrm{~g} / \mathrm{kg}, p<0.0001 v s$. the high-salt control group). Candesartan and enalapril further reduced left ventricular mass in DS rats receiving the low-salt diet $(p<0.0001 \quad v s$. the vehicle-treated group). There was no difference in left ventricular mass between the candesartan- and enalapril-treated rats. The effects of chronic treatment with candesartan and enalapril on body weight gain were negligible in DS rats.

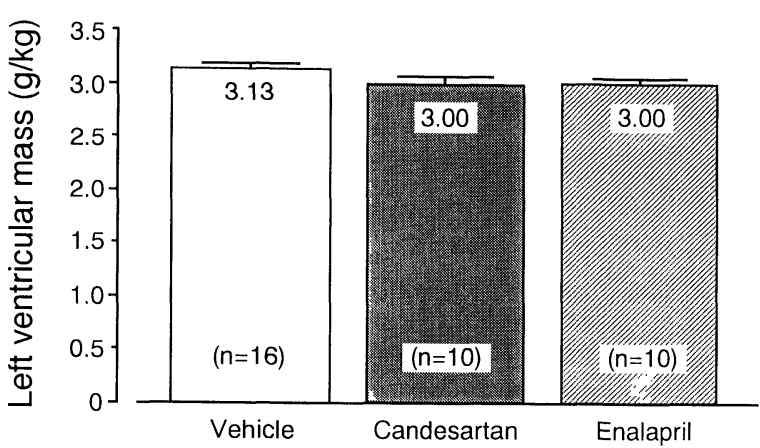

Fig. 3. Bar graph shows left ventricular mass in saltloaded Dahl salt-sensitive rats treated with vehicle, candesartan, or enalapril for $6 \mathrm{wk}$. Bars represent means $\pm S E M$.

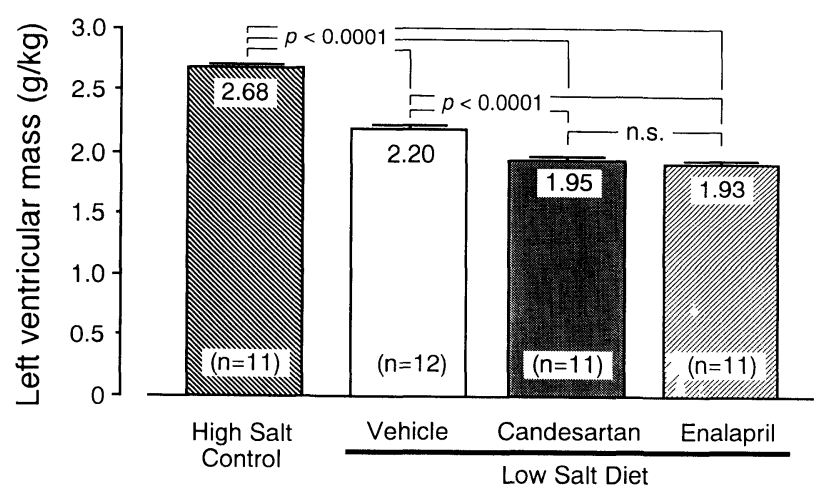

Fig. 4. Bar graph shows left ventricular mass in Dahl salt-sensitive rats given an $8 \%$ salt diet for $8 w k$ (high-salt control) and in Dahl salt-sensitive rats switched from an $8 \%$ salt diet to a $0.3 \%$ salt diet. Salt-depleted rats were cotreated with vehicle, candesartan, or enalapril for $5 w k$. Bars represent means $\pm S E M$.

\section{Plasma Renin Activity}

PRA at the end of treatment in experiments 1 and 2 are shown in Table 1 . In the vehicle-treated group, PRA was not suppressed after 9 wk of an $8 \% \mathrm{NaCl}$ diet. Both candesartan and enalapril slightly increased PRA in DS rats fed an $8 \% \mathrm{NaCl}$ diet. In experiment 2, PRA in DS rats (the high-salt control) remained low after an $8 \% \mathrm{NaCl}$ diet for $8 \mathrm{wk}$. After the diet was switched from $8 \%$ to $0.3 \% \mathrm{NaCl}$ content, PRA increased slightly but not significantly in the vehicle group. Cotreatment with candesartan and enalapril increased PRA in the sodium-deleted DS rats.

\section{Discussion}

The present study demonstrated that blockade of the RAS with an $\mathrm{AT}_{1}$ antagonist or an ACE inhibitor failed to reduce left ventricular mass and elevated blood pressure in DS rats fed an $8 \%$ salt diet. In experiment 1, PRA in the vehicle-treated DS rats did not remain low after a high dietary salt intake for $9 \mathrm{wk}$. High sodium loading suppresses 
Table 1. Plasma Renin Activity in Salt-Loaded and -Depleted Dahl Salt-Sensitive Rats After Chronic Treatment with Vehicle, Candesartan $(3 \mathrm{mg} / \mathrm{kg} / \mathrm{d})$, or Enalapril $(30 \mathrm{mg} / \mathrm{kg} / \mathrm{d})$

Experiment 1

\begin{tabular}{ccccc}
\hline & Vehicle & Candesartan & Enalapril & $p$ \\
\hline$n$ & 16 & 10 & 10 & $5.8 \pm 1.1$ \\
PRA $(\mathrm{ng} / \mathrm{ml} / \mathrm{h})$ & $3.5 \pm 0.5$ & $5.3 \pm 1.9$ & 0.297 \\
\hline
\end{tabular}

Experiment 2

\begin{tabular}{|c|c|c|c|c|c|}
\hline & \multirow{2}{*}{ High-salt control } & \multicolumn{3}{|c|}{ Low salt diet } & \multirow{2}{*}{$p$} \\
\hline & & Vehicle & Candesartan & Enalapril & \\
\hline$n$ & 11 & 12 & 11 & 11 & \\
\hline PRA (ng/ml/h) & $0.4 \pm 0.1$ & $4.1 \pm 1.0$ & $19.6 \pm 5.3^{*, \S \S}$ & $17.0 \pm 4.4^{\S}$ & 0.0004 \\
\hline
\end{tabular}

PRA, plasma renin activity. Data are means \pm SEM. $p$ by one way ANOVA. ${ }^{*} p<0.05 v s$. vehicle, ${ }^{\S} p<0.05,{ }^{\S} p<0.01$ $v s$. high salt control.

PRA in DS rats during the initial 4 wk and then increases PRA (4). PRA in the vehicle-treated animals was comparable to that in DS rats given an $8 \%$ salt diet for 6 to $10 \mathrm{wk}$. The rise in PRA after prolonged high-salt loading is probably caused by hypertensive renal vascular damage. It indicates that the circulating RAS in DS rats is activated even when a high-salt diet is continued for a longer period. If long-term high-salt loading activates not only the circulating but also the tissue RAS, enhanced production of cardiac Ang II could participate in the development of LVH in DS rats. It has been reported that candesartan or enalapril regress LVH by suppression of the tissue RAS in spontaneously hypertensive rats $(5,6)$. A low dose (1 $\mathrm{mg} / \mathrm{kg}$ ) of candesartan significantly reduced Ang II content in the left ventricle (5). In our previous experiments, candesartan at the same dose used in this study $(3 \mathrm{mg} / \mathrm{kg})$ markedly suppressed pressor responses to exogenous Ang II in salt-loaded DS rats (3). Enalapril at doses lower than that used in this study reduced left ventricular Ang II content (6) and inhibited plasma and tissue ACE activities (7). Candesartan and enalapril at the doses used in this study are therefore considered to suppress the circulating and tissue RAS in DS rats. In experiment 1 , concurrent RAS blockade with high-salt intake did not reduce left ventricular mass or blunt the blood pressure rise. These results are consistent with our previous findings in rats given a $4 \%$ salt diet as high-sodium loading $(2,3)$. The present and our earlier results suggest that the local RAS may remain suppressed irrespective of circulating RAS status in salt-loaded DS rats or that local RAS may not be involved in the development of cardiac hypertrophy in DS rats given a high-salt diet.

When switched from a high-salt to low-salt diet, blood pressure in the salt-depleted rats decreased slightly but significantly as compared with the highsalt control rats, and candesartan and enalapril lowered blood pressure further. Average PRA in DS rats increased after switching from the high-salt to low-salt diet, and RAS blockade by $\mathrm{AT}_{1}$ receptor antagonism or ACE inhibition greatly lowered blood pressure in salt-depleted DS rats, suggesting that the activated RAS is involved in the mechanism of high blood pressure in salt-depleted DS rats. Salt-depletion alone reduced left ventricular mass in DS rats (18\% reduction), although the reduction in blood pressure was only modest $(-20 \mathrm{mmHg})$. In salt-depleted DS rats, blockade of the RAS normalized blood pressure, while the reduction in left ventricular mass was additive (an 11 to $12 \%$ reduction compared with the vehicle-treated rats). RAS blockade and the consequent reduction in blood pressure thus played a relatively minor role in the decrease in left ventricular mass in DS rats receiving a low-salt diet. LVH in salt-depleted DS rats may regress because of the deprivation of sodium per se or a reduction in hemodynamic load associated with salt-depletion, or both. Several mechanisms could be involved in the regression of $\mathrm{LVH}$ by dietary sodium deprivation. Sodium-depletion may decrease left ventricular mass indirectly via neurohumoral effects. It has been suggested that the trophic effects of increased dietary sodium may involve changes in sympathetic neurotransmitter mechanisms and that dietary sodium intake may increase cardiac $\alpha_{1}$-receptor density (8). Sodium-depletion may decrease adrenergic transmitter release in the left ventricle, contributing to the antihypertrophic effect of dietary sodium. A recent study in rats has shown that restriction of dietary sodium enhances nitric oxide production (9). In rats, LVH caused by chronic inhibition of nitric oxide synthase is unremarkable as compared with the blood pressure elevation $(10,11)$. There is no direct evidence that nitric oxide protects against cardiac hypertrophy in hypertensive models. However, enhanced production of nitric oxide may be involved in regression of LVH during dietary sodium deprivation.

In experiment 2, high-salt loading for $8 \mathrm{wk}$ elevated blood pressure in DS rats; however, the rise in blood pressure was less than that of the rats in experiment 1 . In addition, the left ventricular mass of the high-salt control rats in experiment 2 was also less than that of rats in experiment 1 . Thus it appears that the higher rise in blood pressure during high-salt loading may have caused a greater left ventricular mass in these animals. In experiment 1 , 
RAS blockade did not reduce left ventricular mass significantly. In addition, plasma renin levels remained suppressed even after 8 wk of high-salt loading in experiment 2 . It is thus unlikely that activated local RAS was involved in the development of LVH in the salt-loaded DS rats. These findings suggest that DS rats are heterogenous with respect to salt-sensitivity and response to blood pressure and that hemodynamic load is an important determinant of LVH in DS rats given a high-salt diet.

High sodium intake has a trophic effect on left ventricular mass. In patients with hypertension, a close relation between high sodium intake and the presence of LVH has been shown in several crosssectional studies (12-15). In addition, dietary sodium restriction decreases left ventricular mass (16). The underlying mechanisms by which salt intake causes LVH involve elevated preload and afterload, the sympathetic nervous system, and the RAS. Hypertensive patients with high plasma Ang II concentrations relative to sodium excretion have a greater left ventricular mass than those with relatively low levels of Ang II (17). These findings suggest that impaired suppression of the RAS by salt-loading may influence the development of LVH in hypertensive patients with a high dietary intake of salt. Sodium and Ang II might have additive actions on myocardial hypertrophy in some patients with a high dietary salt intake. In the present study, RAS blockade coupled with high salt intake induced only mild reduction of left ventricular mass in DS rats. It is thus unlikely that Ang II promotes $\mathrm{LVH}$, at least in salt-loaded DS rats.

In agreement with our previous studies, the activation of the RAS does not appear to be involved in the development of LVH, at least in saltloaded DS rats. Losartan has been reported to lower left ventricular mass in DS rats fed an $8 \%$ sodium diet (18). In that study, losartan reduced left ventricular wall thickness and attenuated an increase in left ventricular chamber dimension as assessed by M-mode echocardiography, with a mild reduction in blood pressure. The mechanism of the antihypertrophic effect of Ang II receptor blockade by losartan is unclear. Because losartan lowers blood pressure in salt-loaded DS rats, decreased pressure and volume overload could reduce left ventricular mass. Similarly, blockade of the RAS slightly but insignificantly decreased left ventricular mass in salt-loaded DS rats in association with mild attenuation of the rise in blood pressure, suggesting that a decrease in hemodynamic load due to RAS blockade may reduce LVH in salt-loaded DS rats. It is still unclear whether or not Ang II receptor antagonism directly reduces hypertrophy of cardiomyocytes in the left ventricle of salt-loaded DS rats.

In summary, blockade of the RAS by $\mathrm{AT}_{1}$ receptor antagonism or ACE inhibition failed to reduce left ventricular mass in DS rats receiving a high-salt diet, suggesting that Ang II may not be involved in the development of LVH in these animals. Salt-depletion alone decreased LVH in DS rats and lowered blood pressure slightly. Salt-depletion plus
RAS blockade reduced left ventricular mass mildly in DS rats and normalized blood pressure. A trophic effect of sodium and hemodynamic load may be the major determinants of the development of LVH in DS rats receiving a high-salt intake. The RAS apparently does not act as a stimulus for $\mathrm{LVH}$ in salt-loaded DS rats.

\section{Acknowledgements}

The authors thank Takeda Chemical Industries Ltd. (Osaka, Japan) and Banyu Pharmaceutical Co. Ltd. (Tokyo, Japan) for supplying candesartan and enalapril, respectively. We also thank Kohsai Kido for technical assistance.

\section{References}

1. Kojima M, Shiojima I, Yamazaki T, et al: Angiotensin II receptor antagonist TCV-116 induces regression of hypertensive left ventricular hypertrophy in vivo and inhibits the intracellular signaling pathway of stretch-mediated cardiomyocyte hypertrophy in vivo. Circulation 1994; 89: 2204-2211.

2. Sugimoto $\mathrm{K}$, Gotoh E, Takasaki I, et al: Cardiac hypertrophy and the blockade of angiotensin II receptors by losartan in salt-loaded Dahl salt-sensitive rats. Hypertens Res 1994; 17: 199-203.

3. Sugimoto $\mathrm{K}$, Gotoh E, Takasaki I, et al: $\mathrm{AT}_{1}$ receptor antagonist, TCV 116, does not prevent cardiac hypertrophy in salt-loaded Dahl salt-sensitive rats. Clin Exp Pharmacol Physiol 1996; 23: 282-286.

4. von Lutterotti N, Camergo MJF, Campbell WG, et al: Angiotensin II receptor antagonist delays renal damage and stroke in salt-loaded Dahl salt-sensitive rats. J Hypertens 1992; 10: 949-957.

5. Mizuno K, Niimura S, Katoh K, Fukuchi S: TCV116 , a newly developed angiotensin II receptor antagonist, induces regression of cardiac hypertrophy through suppression of the tissue renin-angiotensin system in spontaneously hypertensive rats. Life $\mathrm{Scl}$ 1994; 54: 1987-1994.

6. Nagano M, Higaki J, Mikami H, et al: Converting enzyme inhibitors regressed cardiac hypertrophy and reduced tissue angiotensin II in spontaneously hypertensive rats. J Hypertens 1991; 9: 595-599.

7. Hirsch AT, Talsness CE, Smith AD, Schunkert H, Ingelfinger JR, Dzau VJ: Differential effects of captopril and enalapril on tissue renin-angiotensin systems in experimental heart failure. Circulation 1992; 86: $1566-1574$.

8. Meggs LG, Ben-Ari J, Gammon D, Goodman AI: Myocardial hypertrophy: the effect of sodium and the role of sympathetic nervous system activity. Am J Hypertens 1988; 1: 11-15.

9. Nishimura M, Takahashi H, Nanbu A, Ohtsuka K, Yoshimura M: Restriction of dietary sodium may enhance nitric oxide production in rats. Hypertens Res 1997; 20: 57-60.

10. Arnal F-J, el Amrani A-I, Chatellier G, Menard J, Michel J-B: Cardiac weight in hypertension induced by nitric oxide synthase blockade. Hypertension 1993; 22: $380-387$.

11. Rhaleb N-E, Yang X-P, Scicli G, Carretero OA: Role of kinins and nitric oxide in the antihypertrophic effect of ramipril. Hypertension 1994; 23 (Part 2): 865-868.

12. Daniels SD, Meyer RA, Loggie JMH: Determinants of cardiac involvement in children and adolescents with essential hypertension. Circulation 1990; 82: 
1243-1248.

13. du Cailar G, Riebstein J, Daures J-P, Mimran A: Sodium and left ventricular mass in untreated hypertensive and normotensive subjects. Am J Physiol 1992; 263: H177-H181.

14. Liebson PR, Grandits G, Prineas R, et al: Echocardiographic correlates of left ventricular structure among 844 mildly hypertensive men and women in the Treatment of Mild Hypertension Study (TOHMS). Circulation 1993; 87: 476-486.

15. Kupari M, Koskinen P, Virolainen J: Correlates with left ventricular mass in a population sample aged 36 to 37 years. Circulation 1994; 89: 1041-1050.

16. Jula AM, Karanko HM: Effects on left ventricular hypertrophy of long-term nonpharmacological treatment with sodium restriction in mild-to-moderate essential hypertension. Circulation 1994; 89: 10231031.

17. Schmieder RE, Langenfeld MRW, Friedrich A, Schobel HP, Gatzka CD, Weihprecht H: Angiotensin II related to sodium excretion modulates left ventricular structure in human essential hypertension. Circulation 1996; 94: 1304-1309.

18. de Simone G, Devereux RB, Camargo MJF, Wallerson DC, Sealey JE, Laragh JH: Reduction of development of left ventricular hypertrophy in salt-loaded Dahl salt-sensitive rats by angiotensin II receptor inhibition. Am J Hypertens 1996; 9: 216-222. 